\title{
Stealing is Stealing: A Cross-Cultural Analysis on the Perception of Criminality for Physical Theft Versus Illegal Downloading
}

\author{
Alexius Q. Babb, Department of Psychology, Indiana University Kokomo
}

\section{ABSTRACT}

Tn our technology-driven world, consumers have access to a wealth of product options, but this access also allows consumers the 1 opportunity to obtain purchasable content through illegal means. Past studies have addressed the perceptions of the criminality of online versus face-to-face theft, but limitations have been consistent across studies with the frequent use of collegiate sample pools. It was important for this experiment to gather data from a broader world population to make results more generalizable. Therefore, we examined a total of 589 participants from a global participant pool to evaluate their perceptions of the criminality of online piracy or physical theft of music or software. This experiment hypothesized that (1) the perception of the criminality of illegal downloading of media would be assessed higher ratings by South Asian participants than North American participants, and (2) criminality ratings would be assessed higher ratings by females than males. Participants were randomly assigned to one of four vignettes. They were then asked a series of questions using semantic differential and Likert scales to assess their perception of the criminal act committed in the randomly selected vignette. A one-way ANCOVA and a multiple regression test were performed to test the hypotheses.

KEYWORDS: illegal downloading, criminality, cross-cultural analysis

\section{INTRODUCTION}

The Internet has revolutionized how we communicate, interact, and shop for the items we want and need. This tool allows businesses to market and sell their products directly to consumers, but it also allows consumers to easily access and steal digital content. This is problematic if the criminality of downloading content illegally is not viewed the same as the criminality of physically stealing that same product from a brick and mortar vendor. Can this lack of moral judgment be due to the ability to obtain this content easily? The Internet has made the availability of digital content accessible and manageable, and it has given digital products the ability to be compressed to files that usually retain the same quality of the purchased content (Hinduja \& Ingram, 2009). If the punishment for downloading activity is not enforced as frequently as punishment for theft from a store, consumers may assume what they are doing is harmless. They could also be less inclined to question the legality of downloading. This supports Benjamin's (2002) idea that consumers questioning the terms "illegal downloading" versus "theft" could play a role in how they make their decisions on whether to purchase or obtain this content through illegal means. In order to measure the criminality of illegally obtaining purchasable content and to clear any confusion for survey participants, this study defined "illegal downloading" as unauthorized copying, use, or distribution of: software, music, video, or any other type of digital content (Yu, 2011). "Theft" was defined as the unlawful taking of any property without the consent of the owner. Our primary focus in this study was to determine if there were significant differences regarding the perception of illegal downloading based on nationality and gender among study participants.

Past studies have examined the criminality of illegal downloading, but they primarily focused on perception, morality, risk, and moral judgment of downloading illegal content (Benjamin, 2002), as well as whether illegal downloading is considered socially acceptable (Jambon \& Smetana, 2012). Studies have also investigated whether downloading was seen as morally justifiable when the actions of the person downloading the content, as well as the decision-making process that led to the decision to illegally download purchasable media content (Wu \& Yang, 2013), could not be controlled (LaRose \& Kim, 2007). These were important studies to take into consideration for this research because they looked at factors that could affect 
an individual's ability to view illegal downloading as criminal. Economic and social influences could convince a person to perceive illegal downloading as justifiable even if the individual is aware that their actions are criminal. The perception of criminality with respect to illegal downloading and physical theft becomes difficult because the sense of acceptability and normality develops with an increase in such behaviors. Furthermore, the illegal downloading of media was viewed as more acceptable than other prototypical forms of theft because the harmful consequences of these actions are difficult to identify (Jambon \& Smetana, 2012).

Recalling specific instances of punishment regarding illegal downloading may be difficult for individuals due to the lack of prosecutions by legal entities, lack of known punishments for offenders, and lack of knowledge of the penalties associated with this crime. Without consistent negative punishment to deter illegal downloading, consumers may be left to assume that this behavior is not only acceptable, but that it does not harm the industries that create the products consumers are stealing. Morrow and Downey (2013) provided the basis for assessing online versus faceto-face interactions. Their use of randomly presented vignettes to determine how participants attributed blame in bullying situations was helpful to this research on criminality assessments. In addition, Alicke's (2000) culpable control model for assigning blame provided insight into several possible reasons why consumers may feel justified in their actions to illegally download content. This indicates that consumers may think the creative industry charges too much for their products. Consumers may also believe that artists are not hurt financially from their illegal procurement of media available on the Internet.

Past studies also allowed us to examine consumers' perceptions of illegal downloading and theft; however, results were limited by college sample pools. Wu and Yang (2013) provided insight regarding how college students in China and Taiwan perceived illegal downloading. Their results indicated that moral perceptions of illegal downloading were based on the situational factors in the study despite students indicating illegal
Table 1:

Participant Nationality

\begin{tabular}{|l|c|c|}
\hline \multicolumn{1}{|c|}{ Demographics } & Frequency & $\begin{array}{c}\text { Valid } \\
\text { Percent }\end{array}$ \\
\hline North Americans (e.g., Canada, U.S., Mexico) & 353 & 59.9 \\
\hline Central or South America (e.g., Panama, Honduras, Brazil, Argentina) & 4 & 0.7 \\
\hline The Caribbean (e.g., Cuba, Puerto Rico, Jamaica, Haiti) & 2 & 0.3 \\
\hline Western Europe (e.g., United Kingdom, France, Germany, Greece) & 8 & 1.4 \\
\hline Eastern Europe (e.g., Hungary, Romania, Ukraine, Russia) & 4 & 0.7 \\
\hline East Asia (e.g., China, Japan, South Korea, Thailand, Philippines) & 5 & 0.8 \\
\hline South Asia (e.g., India, Afghanistan, Pakistan & 208 & 35.3 \\
\hline Middle East (e.g., Egypt, Turkey, Saudi Arabia, Iraq, Iran) & 3 & 0.5 \\
\hline Africa (e.g., Algeria, Nigeria, Kenya, South Africa & 2 & 0.3 \\
\hline Total & 589 & 100 \\
\hline
\end{tabular}

downloading as unethical. We determined there was a need to examine this issue on a much larger scale by using a global population to measure the criminality of illegal downloading. We wanted to explore crosscultural differences, which would give us a broader knowledge of how people assessed criminality based on nationality. Therefore, two hypotheses were proposed to test the criminality of illegal downloading. We hypothesized that the perception of the criminality of illegal downloading of media would be assessed higher ratings by South Asian participants than by North American participants. We also hypothesized that criminality would be assessed higher ratings by females than by males.

\section{METHODS}

\section{Participants}

There were 603 adult participants aged 18 to 71, with a mean age of $36.71(\mathrm{SD}=12.14)$ representing nine different nationalities as indicated in Table 1 . The participants included 317 (52.6\%) males, 271 (45.15\%) females, and $14(2.3 \%)$ individuals who chose not to report some important demographic data. Because these 14 participants did not indicate gender, nationality, or race, they were eliminated from the survey. This left us with a total sample of 589 participants. Table 1 provides a description of the sample.

\section{Measures}

Participants were asked basic demographic questions that included race, nationality, age, education, gender, and religion. Participants were also asked if they were 
Table 2:

Survey Vignettes for Illegal Downloading and Physical Theft 1

\begin{tabular}{ll}
\hline Vignettes & \\
\hline $\begin{array}{l}\text { Criminality - Illegal } \\
\text { download of media }\end{array}$ & \multicolumn{1}{c}{$\begin{array}{c}\text { Sam's friend just told him that his favorite artist released a new } \\
\text { album. Upon researching the price of the album, Sam discovers that he } \\
\text { does not have enough money to purchase it. A few hours later, Sam } \\
\text { downloads the album from an online file sharing website to his computer. } \\
\text { Technically, this is a copyright infringement. Sam understands that he is } \\
\text { breaking the law, but he decides to download the album anyway. }\end{array}$} \\
$\begin{array}{ll}\text { Criminality - Illegal } \\
\text { copying of media }\end{array}$ & $\begin{array}{l}\text { Sam's friend just told him that his favorite artist released a new album. } \\
\text { Upon researching the price of the album, Sam discovers that he does not } \\
\text { have enough money to purchase it. A few hours later, Sam borrows his } \\
\text { friend's copy of the album and burns his own copy. Technically, this is a } \\
\text { copyright infringement. Sam understands that he is breaking the law, but } \\
\text { he decides to burn the CD anyway. }\end{array}$
\end{tabular}

Criminality - Illegal

download of software Sam's friend just told him that an exciting new software package has been released. Upon researching the price of the software, Sam discovers that it costs several thousand dollars. A few hours later, Sam downloads the software form an online sharing website to his computer. Technically, this is copyright infringement. Sam understands that he is breaking the law, but he decides to download the software anyway.

Criminality - Illegal copying of software

Sam's friend just told him that an exciting new software package has been released. Upon researching the price of the software, Sam discovers that it costs several thousand dollars. A few hours later, Sam borrows his friend's copy of the software and burns his own copy. Technically, this is copyright infringement. Sam understands that he is breaking the law, but he decides to burn the software anyway.

fluent in the English language. This question was important to include because it ensured participants could accurately answer each question presented in the survey. After the demographic questions were answered, participants read one of four randomly presented vignettes as indicated in Table 2 . These vignettes were constructed to measure several variables related to illegal downloading and physical theft; however, criminality of illegal downloading was the main focus of this study. Following the vignettes were questions that asked participants to rate the criminality of the activity within the randomly presented vignette. This study focused on the vignettes that specifically mentioned theft by illegal downloading.

The main independent variables for this study were gender and nationality based on North American and South Asian participants. The dependent variable of criminality was measured using the four questions located in Table 3. Each question was assessed on a scale from 1 (strongly disagree) to 7 (strongly agree).
Participants' scores for ratings of criminality were calculated by taking the mean from the results of the four questions. The mean score of criminality was 4.26 with a standard deviation of 1.35 .

Procedure

Every aspect of this study was reviewed and approved by the Indiana University Kokomo Institutional Review Board. The survey was placed on Amazon Mechanical Turk for participants to view online. Because participation was anonymous and voluntary, those who chose to complete the survey were not aware beforehand of the identity of the researchers or the university conducting the study. Participants were provided with an informed consent request to review prior to beginning the survey. After informed consent was submitted electronically, the participants were asked questions regarding demographics.

Participants were then presented with one randomly selected vignette to read. Once the vignette was read, participants were then asked to complete a total of 22 questions. When the survey was complete, participants received compensation that totaled one cent per question, with no compensation awarded for incomplete surveys. The data collected through Amazon Mechanical Turk was sent to a password protected secure server only accessible to the primary investigator. The data was then distributed for further analysis.

\section{Statistical Analysis}

Participant demographics were analyzed using descriptive statistics (Table 1). To calculate the ratings of criminality, the mean of four questions was determined, and the reliability of the survey answers was examined

Table 3:

\section{Cronbach's Alpha - Questions Combined for} Mean Criminality

Mean Criminality

(1) Sam has committed a crime

(2) Sam has done something wrong

(3) Criminal action should be taken against Sam

(4) Civil legal action should be taken against Sam 


\section{SOCIALSCIENCES}

Table 4:

\begin{tabular}{lcc}
\multicolumn{3}{l}{ Pearson Correlation Mean Criminality and Age } \\
\hline Correlations & \multicolumn{2}{l}{ Mean Criminality } \\
\hline Pearson Correlation & 1 & $.089^{*}$ \\
Significance & - & .036 \\
$\mathrm{~N}$ & 560 & 552
\end{tabular}

Note. Correlation is significant at the 0.05 level.

using Cronbach's alpha (Table 3). A correlations test was performed to examine possible associations between nationality and age (Table 4 ). To test the hypotheses, independent samples $t$-tests were performed using the dependent variable of criminality and the independent variables of gender and nationality. The nationality variable had 10 possible categories with only nine selected by participants. Due to the high participant responses from North America and South Asia, we decided on these two populations for the nationality variable. A one-way ANCOVA and multiple regression tests were performed controlling for age, gender, and religion using the dependent variable of criminality and the independent variable of nationality.

\section{RESULTS}

We took the mean scores of four questions to establish a new variable for criminality. To test the reliability of that variable, Cronbach's alpha was performed $(\alpha=.78)$, which indicated good reliability as shown in Table 3. To identify possible covariates in the planned ANOVA and regressions, we performed a Pearson's correlations test using the demographic variable of age and the dependent variable of criminality located in Table 4 . There was a small positive association found between criminality and age $(r=.089)$, which demonstrated significance. Data were analyzed by comparing the criminality ratings of North American and South Asian participants and by comparing criminality ratings based on gender. Independent samples tests were performed to test the hypotheses regarding criminality ratings for gender and nationality. The results indicated no significance $(t=-1.91, p=.06)$ in criminality ratings between males $(n=302)$ and females $(n=257)$. The mean criminality score for males was $4.15(\mathrm{SD}=.076)$ while the mean criminality score for females was 4.37 $(\mathrm{SD}=0.85)$. Comparison based on nationality between
North American $(\mathrm{n}=339)$ and South Asian $(\mathrm{n}=192)$ participants indicated significance $(t=-3.78, p<.001)$ in criminality ratings. The North American group had a mean criminality score of $4.11(\mathrm{SD}=1.44)$ and the South Asian group had a mean criminality score of 4.56 $(\mathrm{SD}=1.09)$

We ran a one-way ANCOVA controlling for the covariates of religion, gender, and age. Using the dependent variable of criminality and the independent variable of nationality, the one-way ANCOVA revealed a main effect of nationality with no interaction. When controlling for religion, gender, and age, nationality had a significant effect on criminality, $F(1,550)=213.38$, $\mathrm{p}<.001,\left(\mathrm{R}^{2}=.096\right)$. We then performed a multiple regression test controlling for religion, age, and gender, using nationality as a predictor for the outcome of criminality. The results indicated (when controlling for religion, age, and gender) that nationality had a significant influence on criminality $\mathrm{F}(4,549)=18.88$, $\mathrm{p}$ $<.0001,\left(\mathrm{R}^{2}=.076\right)$.

\section{DISCUSSION}

When examining the findings of this research, the assessment of criminality was found to be scored higher by South Asians than by North Americans, which supports the first hypothesis. However, the assessment of criminality between males and females did not show any significant difference. When comparing gender and nationality, criminality assessments were above the median score of 3.5. However, the scores were relatively close to the median. When religion, age, and gender were eliminated, the effect of nationality had a significant impact on criminality scores. Could this indicate that individuals who know illegal downloading is wrong do it anyway because the digital products are easily accessible? If so, what does this say about how individuals in this study viewed the criminality of illegal downloading? Even though illegal downloading was assessed as criminal, such a finding suggests that the criminality ratings were not as strong as expected. There was no effect when gender was analyzed, but nationality played the greatest role in the scoring of criminality. This is interesting because while the act of illegal downloading is stealing, the low ratings of criminality suggest that other factors may contribute to 
why this is not viewed as criminal.

The low assessment of criminality in this study could relate to Benjamin's (2002) study, which identified how questioning the terms "illegal downloading" versus "theft" could play a role in how consumers make their decisions. This was important to identify because the effects of nationality within this study could indicate a lack of uniformity regarding illegal downloading laws and financial penalties. In real-world applications, the free access of digital content on the Internet could aid the perceived low criminality of illegal downloading. The platform on which it is available gives so much access with little to no policing. The lack of punishment for illegal downloading could lead consumers to assume this activity is acceptable and that their illegal downloading activity does not negatively impact the creators of these digital products.

Secondly, the idea that questioning the legalities of downloading can affect decision-making processes that lead to criminal actions aligns with $\mathrm{Wu} \&$ Yang's results (2013). One example is the global recession, which may have played a role in making individuals rethink their everyday purchases. Suddenly, necessities were the focus of household budgets and non-essentials items were less important because they were still accessible on the Internet. This idea begs the question: if illegal downloading is not seen as criminal, and there is no consistent form of punishment, should consumers be punished for illegal downloading? The only instances of individuals being convicted of illegal downloading are those of extreme cases, which are rare. If individuals become accustomed to not paying for content during periods of financial stress, these actions may set the stage for future replications of such acts over long periods of time. Consumers would not question the legality of downloading if punishment was consistent.

Lastly, the low scores of criminality observed in this study could indicate that this activity has become more socially acceptable, a concept which agrees with Jambon \& Smetana's (2012) findings. The mean age of the sample was 36.71. This could further suggest that individuals who grew up with technology and access to websites such as Napster, Kazaa, Scour Exchange, and Freenet viewed illegal downloading as socially acceptable. There are many ways to acquire cyber products for free.
Technologically savvy individuals can easily obtain what they need with no remorse, especially when the creators of the products do not appear to show signs of financial stress due to illegal downloading.

\section{CONCLUSION}

Overall, there were several limitations to this study. Given the low ratings of criminality, socioeconomic factors, such as a lack of financial means, could influence a person to illegally download media. Another limitation is how the crowdsourcing tool was used to solicit survey participants. Amazon Mechanical Turk is a paid platform. This could affect the generalizability of survey results because payment could affect how questions are answered. However, $65 \%$ of the sample had a college level education and the computer skills necessary to navigate the Amazon Mechanical Turk system. Each participant indicated they were fluent in English, had access to the Internet to take the survey, and took the survey voluntarily. This reflects the identical criteria that would be implemented if the survey was presented to non-paid participants.

Future research could focus on religious factors and the perception of punishment towards illegal downloading. In order to get the full picture of what motivates this illegal activity, religion and punishment should be studied. Religious beliefs could influence how a person would assess criminal actions. In addition, people who assume they will not be caught or punished for this behavior may be more inclined to continue illegal downloading, which could be indicative of greater social acceptability. The realistic impact of illegal downloading on the creative industry could also be included. This research could provide a bridge between the opinions of consumers and creative industries to examine the need of lowering product costs or creating stricter regulations for releasing content on the Internet.

\section{ACKNOWLEDGMENTS AND CORRESPONDENCE}

The author would like to thank Susan Sciame-Giesecke and Indiana University Kokomo for valuing student research and providing funding to conduct and present the findings of this research at the Indiana University Undergraduate Research Conference and the National Conference on Undergraduate Research. A special thank you to Christina Downey for securing the applied learning grant needed to conduct this study. In addition, her knowledge of scientific research methods and her guidance 


\section{INDIANA UNIVERSITY JOURNAL OF UNDERGRADUATE RESEARCH}

\section{SOCIAL SCIENCES}

throughout this study was crucial to its success. The author thanks Christina Russell, Antonia Sawyer, Jayson Cloud, and her experimental psychology class. Their collaboration and help during the origination of this survey, peer editing process, and encouragement was beneficial to the completion of the research article.

All correspondence concerning this article should be addressed to Alexius Q. Babb at aqbabb@iuk.edu

\section{REFERENCES}

Alicke, M. (2000). Culpable control and the psychology of blame. Psychological Bulletin, 126(4), 556-574. doi:10.1037/00332909.126.4.556

Benjamin, T. (2002). Understanding consumer ethical decision making with respect to purchase of pirated software. Journal of Consumer Marketing, 19(2/3), 96-111. doi:10.1108/07363760210420531

Hinduja, S., \& Ingram, J. (2009). Social learning theory and music piracy: The differential role of online and offline peer influences. Criminal Justice Studies, 22, 405-420. doi:10.1080/14786010903358125

Jambon, M., \& Smetana, J. (2012). College students' moral evaluation of illegal music downloading. Journal of Applied Developmental Psychology, 33(1), 31-39. doi:10.1016/j. appdev.2011.09.001

LaRose, R., \& Kim, J. (2007). Share, steal, or buy? A social cognitive perspective of music downloading. Cyberpsychology and Behavior, 10(2), 267-277. doi:10.1089/cpb.2006.9959

Morrow, A., \& Downey, C. (2013). Perceptions of adolescent bullying: Attributions of blame and responsibility in cases of cyber-bullying. Scandinavian Journal of Psychology, 54 (6), 536-540. doi:10.1111/sjop.12074

Wu, W., \& Yang, H. (2013). A comparative study of college students' ethical perceptions concerning internet piracy. Quality and Quantity, 47(1), 111-120. doi:10.1007/s11135-0119506-1

Yu, S. (2011). Digital piracy and stealing: A comparison on criminal propensity. International Journal of Criminal Justice Sciences, 5(2), 239-250.- 